\title{
Community Adaptation to Climate Change: Case of Gumuz People, Metekel Zone, Northwest Ethiopia
}

\author{
Abbebe Marra Wagino and Teshale W. Amanuel
}

\section{Contents}

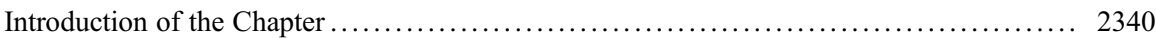

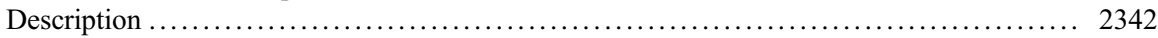

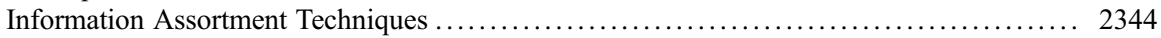

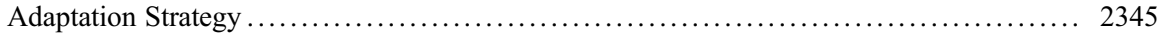

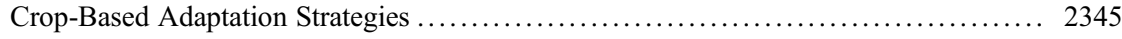

Livestock-Based Adaptation Strategies ................................... 2348

Forest Resources-Based Adaptation Strategies ................................ 2353

Off-Farm Activities as an Adaptation and Other Copping Strategies ................ 2354

Interaction of Policy-Driven and Autonomous Community Resilience to Climate

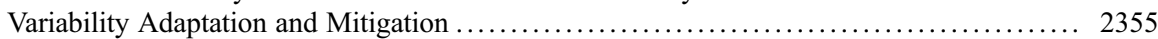

Conclusions and Recommendations of the Chapter............................ 2359

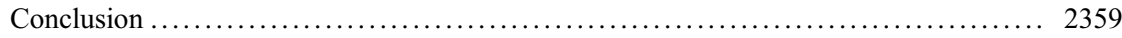

Recommendations .................................................. 2360

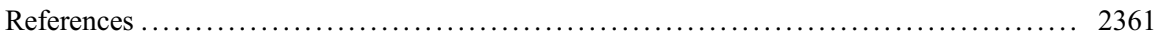

\section{Abstract}

The effect of climate change on agricultural-dependent communities is immense. Ethiopia in which more than $85 \%$ of its population is agrarian is affected by climate change. Communities in different parts of the country perceived climate change and practice different climate change adaptation strategies. This chapter was initiated to identify adaptation strategy to the impact of changing

This chapter was previously published non-open access with exclusive rights reserved by the Publisher. It has been changed retrospectively to open access under a CC BY 4.0 license and the copyright holder is "The Author(s)". For further details, please see the license information at the end of the chapter.

A. M. Wagino (殴

Mendel University in Brno Project in Ethiopia, Addis Ababa, Ethiopia

T. W. Amanuel

Wondo Genet College of Forestry and Natural Resource, Hawassa University, Hawassa, Ethiopia 
climate. Data on a total of 180 households were gathered using structured and semi-structured questioners. Focus group discussion and key informant interview were also used for data collection. Climatic data from the nearest meteorological stations of the area were collected and used in this chapter. The collected data were analyzed using descriptive and inferential statistical methods. The upshot indicated that all the respondent communities experienced at least one of autonomous/self-adaptation strategies to cope and live with the impacts of changing climate. Though $33.6 \%$ complained on its accessibility and pricing, $66.4 \%$ of the respondents reviled as they do not have any awareness on improved agricultural technologies. The major adaptation strategies identified were collecting and using of edible wild plants and other forest products, hunting, renting/selling of own farm lands, livestock sell, selling of household materials/ assets, collecting and selling of wood and wood products and depending on welloff relatives, using drought-resistant crop variety, changing cropping calendar, replanting/sowing, and increasing farmland size. Nevertheless, the communities are not yet fully aware and accessed to policy-driven options for climate change adaptation. Although they used different autonomous adaptation mechanisms, the households are not resilient to the current and perceived climate change. Finally, based on the findings, the recommendation is that besides encouraging the existing community-based adaptation strategies planned adaptation strategies have to be implemented: such as early-warning and preparedness programs have to be effectively implemented in the area, introduction of different drought-resistant locally adapted food crop varieties, and expansion of largescale investment in the area has to be checked, and give due recognition to forest ecosystem-based adaptation mechanisms of the local community in the area.

\section{Keywords}

Climate change $\cdot$ Adaptation strategy $\cdot$ Autonomous adaptation $\cdot$ Planned adaptations $\cdot$ Forest ecosystem $\cdot$ based adaptation options

\section{Introduction of the Chapter}

The world's climate has already changed and will change dramatically. Under the no emission scenario, the average global surface temperature is predicted to increase by $2.8{ }^{\circ} \mathrm{C}$ during this century (IPCC 2007). It is now a challenge for the entire world with growth, poverty, food security, and stability implications. The demand of the hour is to adapt to the changing climate and work together to find mitigation options so that no further damage is done (IPCC 2007).

However, the impacts of existing and predicted changes in climate vary across economies. Poor countries can incur huge costs from a small deviation in climate, particularly due to their dependency on climate-sensitive sectors (Agriculture), poor adaptive capacity, lack of necessary technology, and lack of resources to deal with the stress (Seo and Mendelsohn 2008). For instance, because of significant dependence on the agricultural sector for production, employment, and export revenues, 
Ethiopia is seriously threatened by climate change, which contributes to frequent drought, flooding, and rising average temperatures (Emerta 2013). Severe droughts often are followed by severe food insecurity, population dislocation, family separation, and erosion of the sociocultural fabric (Berhe and Butera 2012).

Like most parts of Ethiopia, climate change brings newer and more complicated challenges to people in Benishangul Gumuz region, having devastating implications for the peoples of the region in general and the Gumuz communities in particular (Emerta 2013). The incidence of crop pests and disease increased from time to time, the size of their forest ecosystem is threatened due to farmland and settlement encroachment by other ethnic groups (Abbute 2002). The existing socioecological system is reduced to support the Gumuz community to cope and live with the new climate stimuli as usual by traditional means. This coupled with their temporally and spatially cyclical agricultural system that involves clearing of land - usually with the assistance of fire - followed by phases of cultivation and fallow periods with the help of rudimentary labor-intensive farm tools threatened the lives of the people in the region. Particularly, the study area is highly affected by climate change and variability. As Sani et al. (2017) indicated the overall natural resources base of the region is highly degraded. Thus, people in the region are facing a variety of shocks and become vulnerable. However, the Gumuz community in the area has been responding to climate change through various adaptation strategies. However, there was no scientific study that substantiates or supports the existing adaptation strategies practiced by the Gumuz people in the area.

Identification of traditional risk mitigation and coping strategies that explicitly show elasticity of the community to existing disturbances in order to evaluate the suitability of current adaptive behaviors, as well as assess the adaptation deficit of local communities in view of increasing climate variability is very important. It would help in identifying those available adaptive measures/options that need to be built on and strengthened, as well as innovative adaptation strategies that add value to current climate risk mitigation and coping behaviors, by effectively addressing adaptation constraints experienced by communities (Berhe and Butera 2012). The knowledge of local adaptation strategies are essential to cope, adapt, and live with current and perceived extreme climate variabilities/changes through building their indigenous resilience mechanisms (WFP and FAO 2012). Therefore, knowing and building community adaptation practice is indispensable to live in the midst of the change. In addition, despite the huge potential that traditional knowledge offers for climate change adaptation, research efforts on the effectiveness and appropriateness of this knowledge have, so far, been limited. Furthermore, there are no proven approaches to integrate traditional coping mechanisms into mainstream development efforts (Berhe and Butera 2012).

Berhe and Butera (2012) indicated that drought and climate variability are part of the natural cycle in lowland Ethiopia, and the communities do have an array of traditional coping mechanisms. Indigenous peoples are excellent observers and interpreters of change on the land, sea, and sky. Moreover, indigenous knowledge provides a crucial foundation for community-based adaptation and mitigation actions that can sustain resilience of social-ecological systems at the interdependent local, regional, and global scales. However, the ability of a community to maintain a certain level of 
well-being in the face of risks depends on the resource options available to that community/household to make a living and on their ability to handle risks (Alinovi et al. 2009). Therefore, this study aimed at investigating the climate change adaptation strategies practiced by the Gumuz people in response to its adverse effects and analyzing determinants of the use of adaptation strategies in copping, adapting, and living with observed and perceived climate variability in the area.

\section{Description}

Location: Metekel Zone is located in the Benishangul Gumuz National Regional State (BGNRS) (Fig. 1). The zone occupies an estimated total area of $22,028 \mathrm{~km}^{2}$. Geographically it is located between $09.17^{\circ}$ and $12.06^{\circ}$ north latitude and $34.10^{\circ}$ and $37.04^{\circ}$ east longitude. The zone encloses seven woredas/districts, namely Bullen, Dibate, Dangur, Guba, Mandura, Pawi, and Wembera. The Addis Ababa-Guba and Chagini to Wombera all-weather road provide the primary access to the area. In the present administrative context, most of the Gumuz inhabit Metekel zone to the north and Kamashi zone to the south of the Abbay/Nile River.

Agro-ecologically, the zone is mostly classified as $82 \%$ lowland (kola), $10 \%$ midland (woina-dega), and $8 \%$ highland (dega) with an average rainfall of $1,275 \mathrm{~mm}$

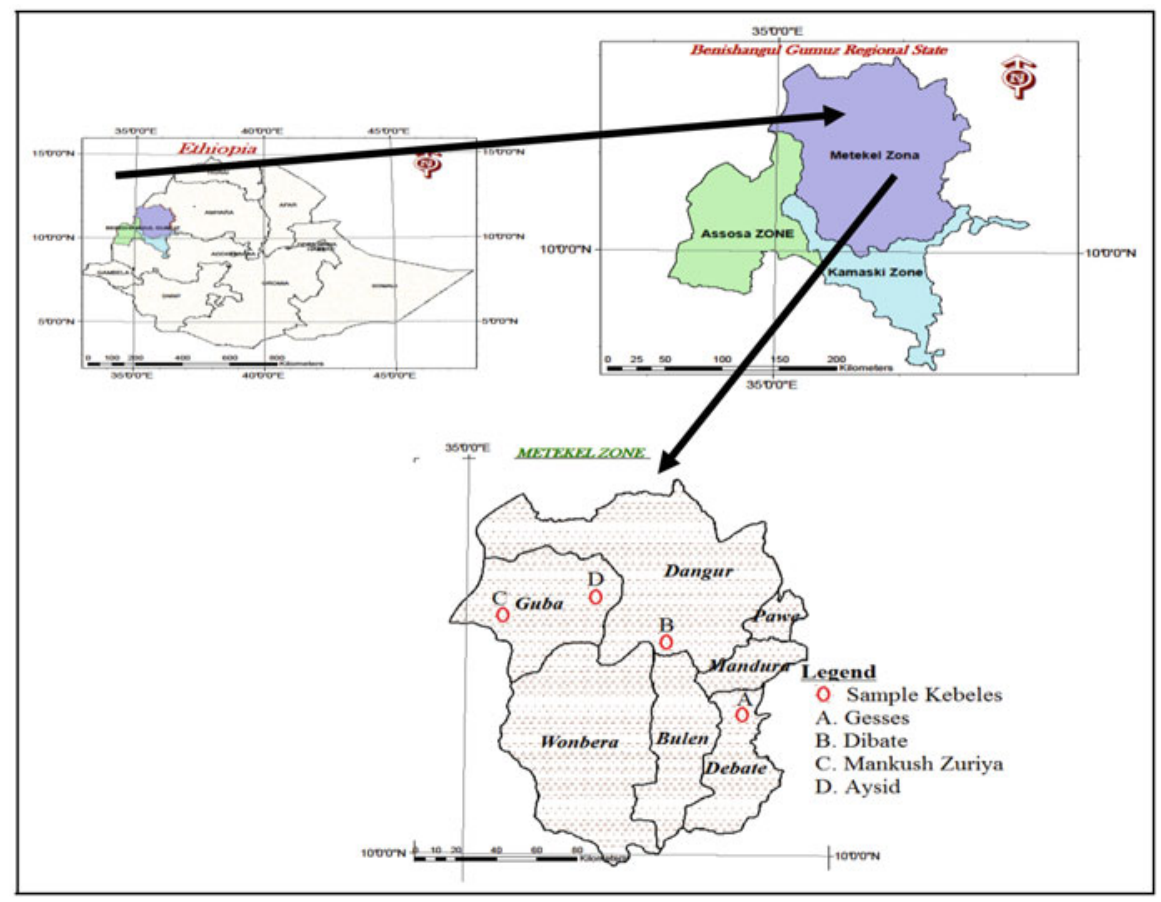

Fig. 1 Map of Metekel zone 
per annum and an altitude range of 500-2731 meter above sea level. The Gumuz, who constitute the most numerous ethnic group of the area, mostly inhabit the lowlands in all seven districts. The total population of the zone was 276,367 (male 139,119 and female 137,248) of which 238,752 are rural setup while the remaining 37,615 are urban dwellers (BGRSDGA 2010). The land use pattern is estimated as $79 \%$ forestland, $7 \%$ cultivated land, $7 \%$ cultivable land, and $7 \%$ nonutilizable land.

The annual average temperature ranges from $16.2^{\circ} \mathrm{C}$ to $32.5^{\circ} \mathrm{C}$ with annual mean rainfall of $1,607.8 \mathrm{~mm}$, where the annual rainfall months ranging from May to October (EARO-PRC 2000). The zone has a unimodal rainfall pattern, with an extended rainy season, from March to September. The peak rainy season is from July to August. The coldest months are December and January whereas March and April are the hottest months of the area (Esayas 2003). The mean monthly available meteorological data obtained from Ethiopian Metrological Agency for the four stations namely Bullen, Mandura, Debate, and Guba for the period of 1972 to 2013 is presented in Fig. 2.

Vegetation: Generally, about 55\% of the total land area of the region is covered with different vegetation and forests. Bamboo, incense, and gum trees are the major forest types. Forests are important sources of construction material, fuel wood, and food, particularly for the indigenous communities (Benishangul Gumuz Region Food Security Strategy 2004). The original plant cover of the Metekel zone constitutes dense hyparrenia, dense bamboo thickets, and scattered trees and of arboreal and thick shrub by formations along the water ways covering areas of various sizes (Dieci and Viezzoli 1992). Degradation of forest resources is increasing at an alarming rate due to various limitations. Encroachment, forest fires, absence of well-defined land use policy, and intensive resettlement programs that took place during the past government regime are some of the main causes for the depletion of natural resources in the region.

Socioeconomic condition: The regional economy depends on agriculture which accounts for $93.2 \%$ of the economically active population. Shifting cultivation is the major economic activity of the Gumuz community. Shifting cultivation is broadly

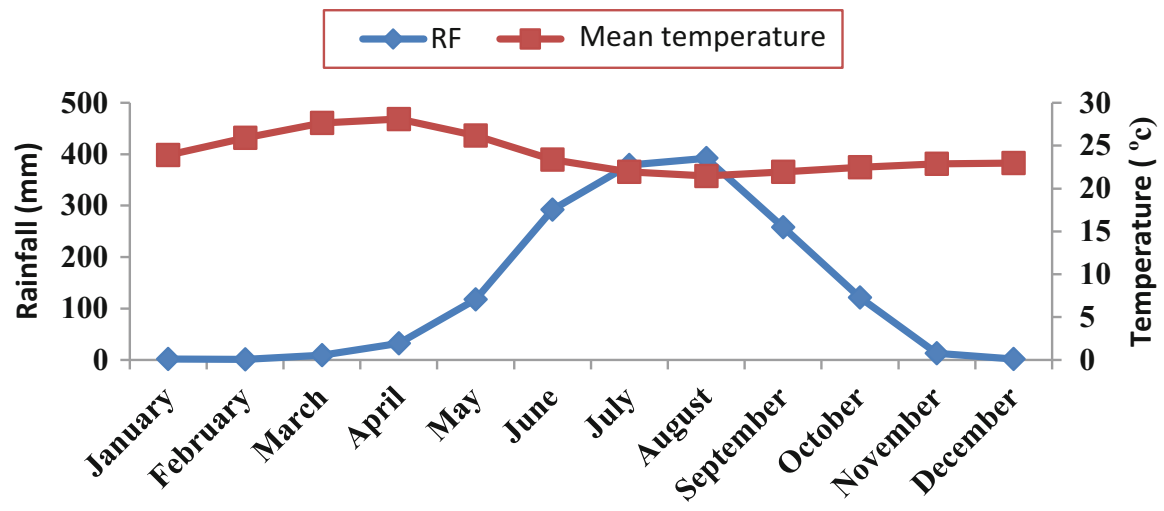

Fig. 2 Mean monthly rainfall and temperature of the study area 
defined as "any temporally and spatially cyclical agricultural system that involves clearing of land usually with the assistance of fire followed by phases of cultivation and fallow periods. The subsidiary livelihood sources include livestock raising, gathering wild foods, fishing, honey production and collection, traditional gold mining, hunting, handicrafts, petty trade and charcoaling" (Anonymous 2004, 2011).

Rudimentary labor-intensive farm tools usage, prevalence of crop diseases, pests and weeds, declining soil fertility, inadequate use of improved inputs, erratic rainfall, human diseases such as malaria, poor rural infrastructure facilities like market and road, absence of credit services, and poor working culture of the communities largely due to use of labor-intensive farm tools and low awareness resulted very limited crop production and productivity in the area.

\section{Information Assortment Techniques}

A multistage sampling technique was used to collect information/data. In the first stage, out of the seven woredas (districts) where the Gumuz ethnic groups predominantly live in the zone, three woredas were purposively selected to include different attributes. The Gumuz community lives almost in the same agro-ecological zones in all woredas. Then within the zone Debate, Dangur, and Guba woredas were selected for this study. In the second stage of sampling, kebeles within the selected woredas were selected according to settlement patterns, farming practices, crop varieties, socioeconomic aspects, climate problems, and disasters besides biophysical features.

Accordingly, Gessess kebele consisted of 260 households from Debate woreda, Debate kebele consisted of 228 households from Dangur woreda, Aysid consisted of 244 households, and Mankush-zuriya kebeles consisted of 107 households from Guba woreda were selected. The numbers of farmers in each sample peasant association were different, specific numbers of respondents were selected with probability proportionate to size (PPS) random sampling technique to ensure representativeness of the population. Consequently, more than $20 \%$ sampling intensity was used from each kebele, accounting a total of 180 sample households and interviewed.

Data collection: Both primary and secondary sets of data were collected. The primary data were collected by using tools of household survey (using structured questionnaire and in-person interview), focus group discussion (FGD), and key informant interview (KII). The valuable secondary data were also obtained from various sources including previous scientific studies and reports from Zonal level agricultural department and other concerned organizations. In addition, the climate data (rainfall and temperature data) was obtained from the National Metrology Agency for the year 1972-2013.

Examination: SPSS statistical software (IBM-SPSS software; version 20) was used throughout the statistical analysis. Both qualitative and quantitative techniques were used to inquiry and presented in the forms of interpretations, comparisons, and arguments. In addition, the quantified information collected using PRA (Participatory Rural Appraisal) tools also presented in figures and percentage. The quantitative analyses made use of all descriptive, correlation, and inferential 
statistical techniques. The descriptive statistical techniques applied in the study include percentages and graphs. Correlation statistics was used to determine the associations of the major autonomous adaptation strategies, major determinants of community resilience in copping, adopting and living with the impacts of current and perceived climate extreme events, and the interaction of extracted community resilience building blocks presented in the form of tables.

In all cases the significance of the result was also tested using statistical T-test and chi-square Pearson test in determining the p-value to define the significant variation of the obtained results among sample woredas and relative wealth categories of respondent households.

\section{Adaptation Strategy}

\section{Crop-Based Adaptation Strategies}

Almost all (98.9\%) of the respondent households practice rain-fed agriculture. Out of 180 respondents only two of them, $1.1 \%$, reported to have owned an irrigated land of 0.5 hactar each. The major crop-based autonomous adaptation options include: (1) extension of fallowing period, (2) delaying of sowing period and/or sowing two to three times on a specific plots of land for a single harvest following availability of moisture, (3) adoption of hardy and early maturing crops varieties, and (4) increase farm land size (Table 6).

About $75 \%$ of the respondents use fallowing crop production system of farming practice (Table 1). Plots are cultivated for 1 or 2 years, then left to recover to woodland by lying fallow for 5 or more years. It is a system which involves clearing of irregular plots at some distance from the village by cutting and burning off trees and shrubs prior to tilling with the hoe. The FDG and KII participants indicated as farmers extend their fallowing period as an option to the effect of climate variability. They perceived that extending fallowing period will increase moisture holding capacity and soil fertility of the land which further increase productivity of the land through reducing weed and pest/disease infestation. The contribution of fallowing in reducing crop weed and pest/disease was mainly reported in Dangur woreda. It is also indicated by Nyong et al. (2007) as natural mulches moderate soil temperatures and extremes, suppress diseases and harmful pests, and conserve soil moisture. However, the practice may increase emission of GHG (Green House Gases) since it involves clearing and burning of forest covers. Though the advent of chemical fertilizers usage is highly encouraged by local level government, local farmers largely depended on organic farming with zero tillage practice which is also capable of reducing GHG emissions.

The FGD participants in GubaWoreda of both Mankush-zuriya and Aysid kebeles testified that almost $100 \%$ of the farmers changed the variety of their provenance local crop seeds as an option of adaptation to climate change to lead their subsistence life. As a result of increasing trends of temperature which is subjected to increase the drying period of the season and declining effects of rainfall amount, they forced to 
change the variety of their provenance crop seeds, locally named as "Bobbe/ yeshenkuit" into "Tirkuwash," a sudan crop variety (both crops belong to sorghum bicolour crop type), because of its adaptation to drought and having short period of time on field for harvesting than the local variety. However, they also explained as they preferred the local variety of their own because of its test difference and ease of management on field. During the discussion, it was understood that the local verities were not easily managed to get and visualized. Besides all the respondent households and FGD participants indicated to sow crop seeds at least two to three times per a single season on a specific plots of lands due to irregular rainfall in the area.

Usage of diversified crop production system through mixed cropping (intercropping) is also mentioned by FGD participants and by $66.6 \%$ of respondent farmers (Table 1). This also includes planting more drought-resistant crops with traditionally adopted early-maturing varieties, for example, the farmers sow pumpkin with other lowland crops and start using of its leaf early at the time when it starts emerging leaf. Furthermore, $93.3 \%$ of the respondents have a plan to increase their farm land. The factor that drives respondent households to increase their farm land was mainly due to climate variability that induced food insecurity-related issues (Table 2). As indicated in Table 2, 69.9\% of the respondent indicated shortage of

Table 1 Agricultural crop production system

\begin{tabular}{l|l|l|l|l}
\hline \multirow{2}{*}{ Production system } & \multicolumn{2}{l|}{ Yes } & \multicolumn{2}{l}{ No } \\
\cline { 2 - 5 } & Count & $\%$ & Count & $\%$ \\
\hline Intercropping production system & 120 & 66.6 & 60 & 33.4 \\
\hline Crop rotation production system & 108 & 60 & 72 & 40 \\
\hline Fallowing production system & 135 & 75 & 45 & 25 \\
\hline
\end{tabular}

Table 2 Factors that drive households to increase their farmlands

\begin{tabular}{|c|c|c|c|c|c|c|c|}
\hline \multirow{2}{*}{\multicolumn{3}{|c|}{ Description }} & \multicolumn{4}{|l|}{ Factors } & \multirow{2}{*}{ Total } \\
\hline & & & \multirow{2}{*}{$\begin{array}{l}\text { Low } \\
\text { production } \\
36\end{array}$} & \multirow{2}{*}{$\begin{array}{l}\text { Low } \\
\text { market } \\
\text { prices } \\
0\end{array}$} & \multirow{2}{*}{$\begin{array}{l}\text { Food } \\
\text { insecurity } \\
16\end{array}$} & \multirow{2}{*}{$\begin{array}{l}\text { Other } \\
\text { (specify) } \\
4\end{array}$} & \\
\hline Woreda & Dibate & Count & & & & & 56 \\
\hline & & $\begin{array}{l}\text { \% within } \\
\text { Woreda }\end{array}$ & 64.3 & 0 & 28.6 & 7.1 & 100 \\
\hline & Dangur & Count & 57 & 0 & 2 & 0 & 59 \\
\hline & & $\begin{array}{l}\text { \% within } \\
\text { Woreda }\end{array}$ & 96.6 & 0 & 3.4 & 0 & 100 \\
\hline & Guba & Count & 30 & 2 & 29 & 0 & 61 \\
\hline & & $\begin{array}{l}\text { \% within } \\
\text { Woreda }\end{array}$ & 49.2 & 3.3 & 47.5 & 0 & 100 \\
\hline \multirow{2}{*}{\multicolumn{2}{|c|}{ Total }} & Count & 123 & 2 & 47 & 4 & 176 \\
\hline & & $\begin{array}{l}\% \text { within } \\
\text { Woreda }\end{array}$ & 69.9 & 1.1 & 26.7 & 2.3 & 100 \\
\hline
\end{tabular}


crop production both for market and household consumption, while $26.7 \%$ depicted the existence of food insecurity in general. The rest $2.3 \%$ of the households also reported as others (to support their dependents, ancestors).

To this end, as it was reported by one of key informant interviewee at Dangurworeda, and later confirmed by development agents of the surveyed kebeles, during the critical food shortage months the Gumuz farmers have been taking "one quintals of maize to return two quintals of sesame (locally named as Selit), the known cash crops of the area, aftershocks within the same harvesting year," unless he/she is forced to give a reasonable land of his/her own to the guy so that he/she can plow until return the amount of sesame as promised. This is obvious that it affects the capacity of the community to adapt to the current impacts of climate variability or changes, though they use the system to safe their life when the family face a food shortage induced by variation of rainfall.

Although all of the respondents are engaged in rain-fed agricultural practice, a limited effort made as a planned adaptation option. In this regards, Table 3 shows that $63.8 \%$ of the respondents do not used any kinds of agricultural inputs to maximize their production from agriculture sector, while the rest used either of agricultural inputs indicated in Table 3. As it was reported by KII the overall improved agricultural practice by the Gumuz people in the area are still at demonstration stage.

Table 4 also showed that almost more than $67.5 \%$ of the surveyed households did not have both access and potential to use agricultural inputs with no significance

Table 3 Improved agricultural inputs utilized/practiced or not (in \%)

\begin{tabular}{l|l|l|l|l|l|l|l|l}
\hline & \multicolumn{3}{l}{ Debate } & \multicolumn{2}{l|}{ Dangur } & \multicolumn{2}{l}{ Guba } & \multicolumn{2}{l}{ Total } \\
\cline { 2 - 10 } Improved agricultural inputs & Yes & No & Yes & No & Yes & No & Yes & No \\
\hline Inorganic fertilizer & 7 & 93 & 10.2 & 89.8 & 6.7 & 93.3 & 8 & 92 \\
\hline Improved seeds & 7 & 93 & 3.4 & 96.6 & 35 & 65 & 15.1 & 84.9 \\
\hline Organic fertilizer & 10.5 & 89.5 & 5.1 & 94.9 & 23.3 & 76.7 & 13 & 87 \\
\hline Herbicides chemicals & & 100 & 25.4 & 74.6 & 1.7 & 98.3 & 9 & 91 \\
\hline $\begin{array}{l}\text { Do not used any forms of } \\
\text { agricultural inputs }\end{array}$ & 83.9 & 16.1 & 57.6 & 42.4 & 50 & 50 & 63.8 & 36.2 \\
\hline
\end{tabular}

Table 4 Respondents having access and potential to use agricultural inputs or not

\begin{tabular}{l|l|l|l|l}
\hline Surveyed woredas & & Yes & No & Total \\
\hline \multirow{2}{*}{ Dibate } & Count & 11 & 43 & 54 \\
\cline { 2 - 5 } & $\%$ & 20.4 & 79.60 & 100 \\
\hline \multirow{2}{*}{ Dangur } & Count & 23 & 35 & 58 \\
\cline { 2 - 5 } & $\%$ & 39.7 & 60.3 & 100 \\
\hline \multirow{2}{*}{ Guba } & Count & 21 & 36 & 57 \\
\cline { 2 - 5 } & $\%$ & 36.80 & 63.2 & 100 \\
\hline \multirow{2}{*}{ Total } & Count & 55 & 114 & 169 \\
\cline { 2 - 5 } & $\%$ & 32.5 & 67.5 & 100 \\
\hline
\end{tabular}


difference among surveyed woredas and/or kebeles, beside low level of the community awareness and skills on application of different improved agricultural technologies as depicted by FGD participants. The rest 32.5\% appreciated their own autonomous means adaptation options. Among those who use improved agricultural inputs $36.2 \%$ are also reported that they use the inputs only for cash crop production not yet used for food crop production purpose because of its price. Also they are satisfied in using the existing natural soil fertility in the area with no significance difference among sample woredas and respondent wealth category, as reported. Hence, revisiting of promotional approaches/system in the way that the Gumuz community awareness level and capacity developed to adopt and use introduced technologies as a planned adaptation option to boost the return from crop production in the area which further builds the resilience of the community to adapt to the impact of current and perceived climate extremes.

\section{Livestock-Based Adaptation Strategies}

In addition to agricultural crop farm, $84.1 \%$ of the respondent households have at least one type of animal/livestock husbandry including chicken, with no significant difference among study woredas of sampled kebeles. The household survey and FGD verified as the farmers in the surveyed areas use a mixed farming system besides their dependency on the forest ecosystem to sustain their livelihood. Anonymous (2004) also indicated livestock plays a big role in the livelihood of the community in the areas.

However, $50.3 \%$ of respondents indicated the declining trends of livestock production since the last 5 years which is attributed to shortage of feed $(73.6 \%)$ and stealing of animals (24.7\%). Also $35.8 \%$ of feed shortage perception was associated with shortage of rainfall. In this regards, $97.2 \%$ of respondents use communal grazing land feeding system while $2.8 \%$ feed through hay/silage preparation/zero grazing by their own traditional means. FGD and KII indicated that except Debate woreda where stealing of animals was worthily mentioned and looks after their cattle, the rest sends their cattle to areas where permanent water flows exists, just like wild animals. The cattle return to the village at the beginning of June where new grass started to sprout out. Consumption of milk and milk products including eggs are not common for Gumuz people. However, almost all respondents reported they use selective keeping of livestock like goat and donkey since they have a capacity to adopt climate extremes through feeding leafs of bushes and other by-products of prepared local drinks, respectively. The discussion participants reported they use traditional medicine for their animal health care during their visit periodically.

As a means of adaptation options $91 \%$ of respondents indicated that they sell animals to adopt with the current climate change-induced stress Table 6 . The correlation test results in Table 5 indicated selling of animals negatively correlated with hunting of wild animals and renting/selling of his/her own farm lands. This indicates if a household sells their animals their dependency participation/engagement in hunting of wild animals and renting/selling of his/her 


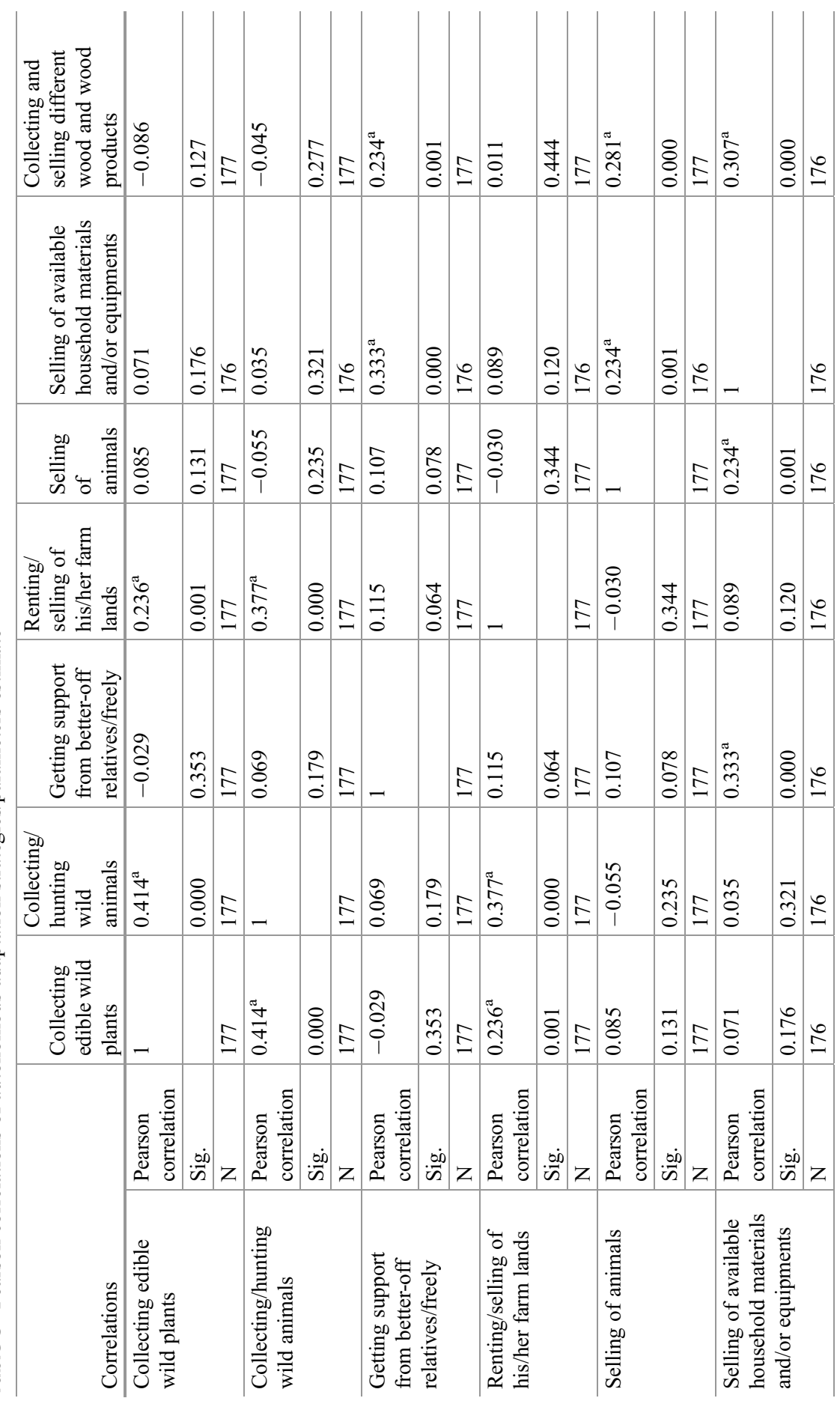




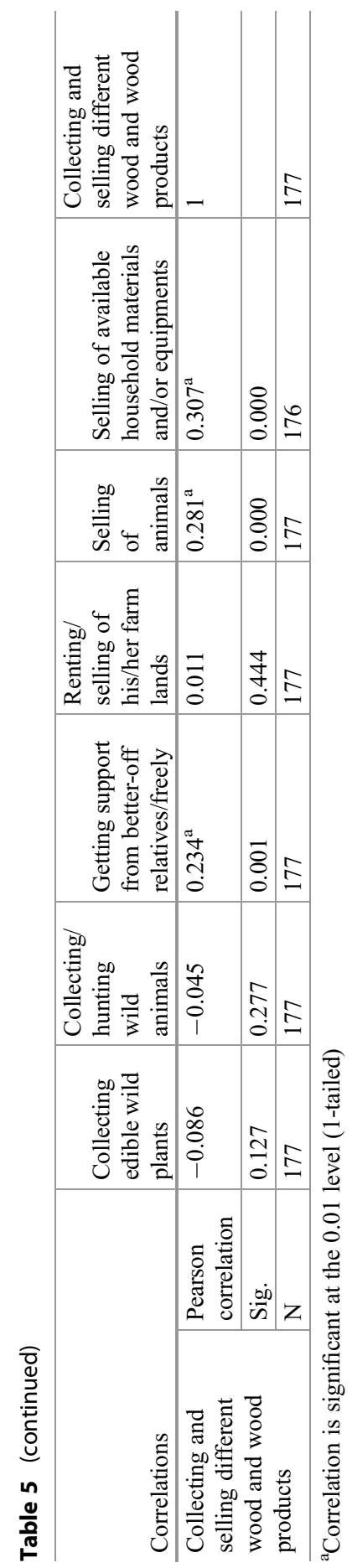




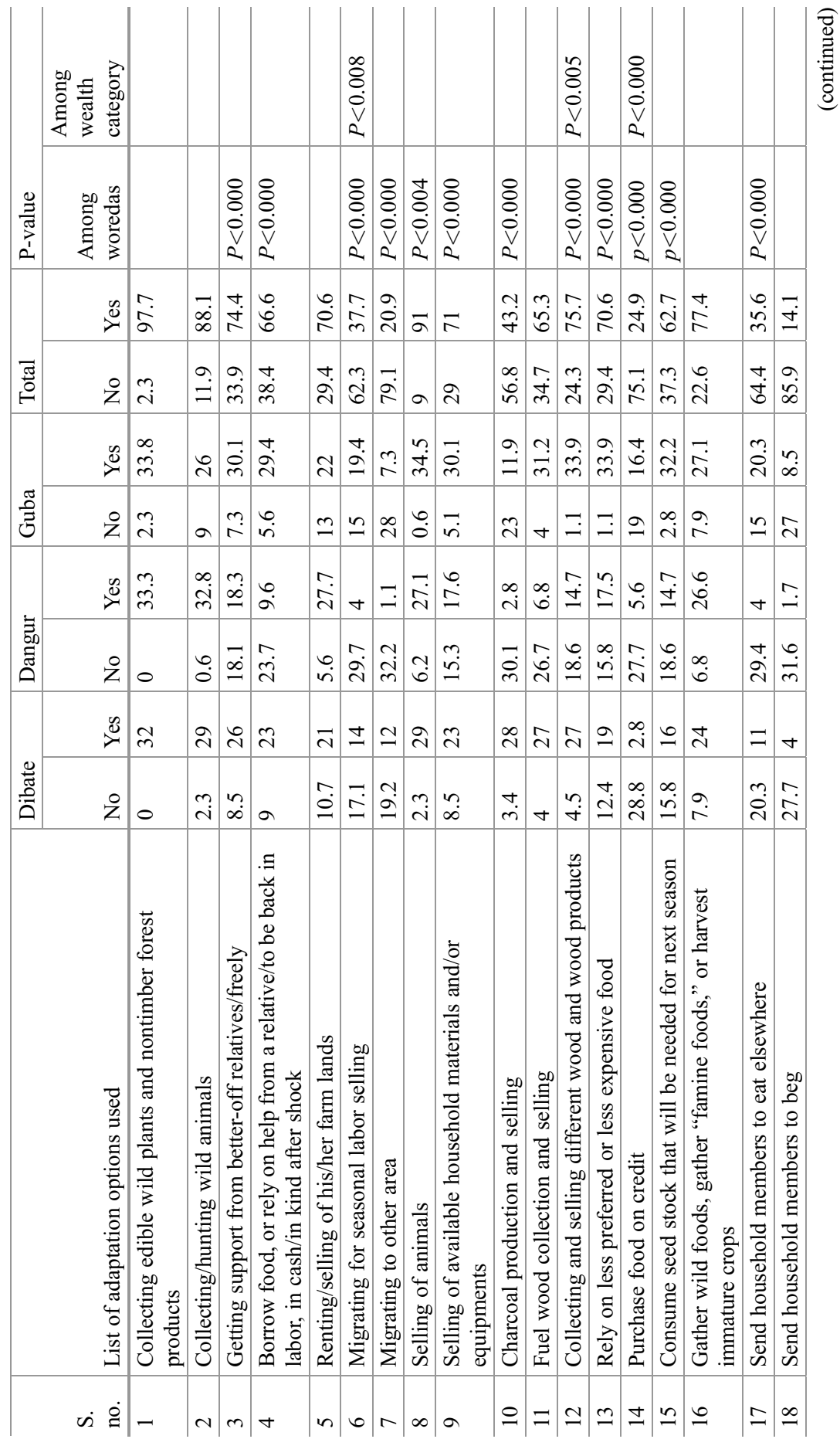




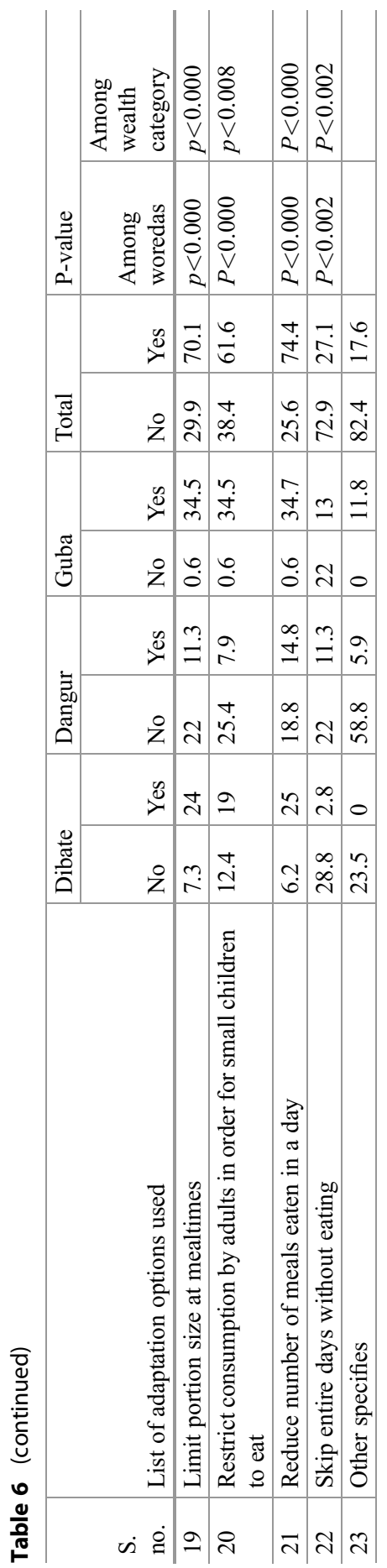


farm land decrease and vice versa. On the other hand, selling of animals positively correlated with other autonomous adaptation option indicated in Table 5 where it is associated with selling of available household materials or equipments and collecting and selling of different wood and wood products are significant at the 0.01 level (Table 5). This depicted that livestock productions are playing a crucial role in copping the impact of climate change and building the resilience of the farmers in the area.

\section{Forest Resources-Based Adaptation Strategies}

The main autonomous coping responses of the household to food shortage caused by drought, erratic rain, and others are presented in Table 6. Most of the respondents $(64.8 \%)$ indicated that climate stress/shock in the study area resulted in declining of crop and animal production. About $53.5 \%$ of the respondents revealed that decline of crop production was associated with variation of rainfall distribution and amount beside other factors. At the time of stress, due to climate change effects, the respondents stated that they are engaged in hunting $(85.1 \%)$, collecting wild edible plants, and other forest products (88.1\%).

On top of this Table 6 it specified that $65.3 \%, 43.2 \%$, and $75.7 \%$ of respondents also engaged on fuel wood selling, charcoal making, and collecting and selling of wood and wood products, respectively. Except collecting and selling of fuel woods which was the same among all woredas and respondents wealth category, the rest of the two (charcoal making and selling of different wood and wood products) have a significant difference among surveyed woredas and wealth category of the respondents. Charcoal making and selling was reported only in Debate woreda. Meanwhile, the large number of respondents from Guba and Debate woreda also conveyed that they engaged on selling of different wood and wood products. In addition, the Pearson correlation test of the major autonomous adaptation strategies indicated in Table 5 shows the existence of strong negative correlation among selling of different wood and wood products with collection of edible wild plants and other forest products, and hunting of wild animals. This may be because of reduced forest resources both in coverage and in its composition to collect edible wild foods and to conduct hunting in Debate and Guba woredas which may be attributed to the existence of large-scale agricultural investment and population pressures than Dangur woredas. As a result, it is also estimated by FGD participants in Debate woreda that the existing tree species reduced by about $40 \%$ as an expense of the lost Bamboo species. Moreover, $16.5 \%$ of respondents depicted that they compensate any low local market prices, if any, by increasing exploitation of nontimber and timber forest products (NTFP and TFP) besides expanding their agriculture farm land.

Hence, forests are playing a pivotal role in climate change adaptation through building their adaptive capacity which further contributes towards building the resilience of the community in the study area beside its climate change mitigation 
role. Therefore, provision of due attention in this sector is indispensable to adapt to the current and perceived impacts of changing climate in a sustainable way.

\section{Off-Farm Activities as an Adaptation and Other Copping Strategies}

Besides crop, livestock, and forest resource-based adaptation strategies mentioned above, $65.5 \%$ of respondents also depend on loan from relatives, $70.6 \%$ on renting/ selling own farm land, and $22.3 \%$ involve in different handcrafts and local beer making to cope, adapt, and live with the impacts of climate change in order to survive their family as another option. The FGD result also indicated that the households engaged on labor selling and renting their farm lands as a means of alternative to pass the food shortage gaps or to live with unexpected happening of climate-induced shocks/stress in the area.

However, it was indicated by respondents that selling or renting of own farm land for the long period of time may affect the monetary values of that land after a long period of time. Likewise, the existence of this problem was also reported by the FGD and KII participants, they stated that when the Gumuz farmers rent their own lands to other ethnic groups who have an experience in oxen farming they use the land intensively to maximize its return. However, they indicated that it is very difficult for Gumuz farmers to manage the land after renting since its pest and weed infestation increase which requires additional cost and labor to maximize the production to which the Gumuz do not have the experience and capacity to afford. Thought it do not have a legal ground, the Gumuz farmers prefer selling of their lands than renting; this may affect their adaptation ability after a long period of time.

In addition, $74.4 \%$ of respondents depend on their better-off relatives to sustain their subsistence life (Table 6). As indicated in the Table 5, looking after relatives for support is negatively correlated with collecting edible wild plants and positively correlated among selling of available household materials or equipments and collecting and selling different wood and wood products with $0.01 \%$ significant level. From this it is understood that farmers seek for support from their relatives after exhausting edible wild plants and actively engaged on selling of his/her household materials, and labor-intensive wood and wood products. The practice may have resulted in loss of self-esteems and ability besides affecting the capacity of their relatives too. The correlation result in Table 5 also revealed that the community considers hunting of wild animals as an alternative means even if it does not replace the food demands of the community in the area. In consistence with the declining trends of vegetation cover as a result of expansion in large agricultural investment, currently it is not easy for the community to hunt wild animals as they accustomed before, though it is positively correlated with other autonomous adaptation options except getting support from better-off relatives and collecting and selling of different wood and wood products.

Selling of available household materials/equipment positively correlated with collecting and selling different wood and wood products $(P<0.000)$. Also getting support from better-off families affirmatively correlated with collecting edible wild 
plants and other products, while most of the others correlated negatively. This correlation synergy results indicated that most of "the traditional/autonomous adaptation strategies are not a choice of the community rather it is a means of survival." For instance, the correlation selling of animals are not significantly correlated with collecting edible wild plants and selling/renting of farm lands as indicated in Table 5. This means, when they sell animals and get money to adapt/cope with observed shocks/stress at a given time the household may be not encouraged in collecting of edible plants, hunting, and others. Hence, the correlation result indicated that the community experienced for ages traditional/autonomous adaptation strategies mentioned that are not a choice of the community, rather a means of survival without which their survival is in question. Hence, this analysis result accentuates the importance and timing of introducing the planned adaptation/copping strategies that influenced the community both by the government and/or other development actors.

However, since the community depends on their traditional means for ages, it is very difficult to influence them overnight to accustom the planned/policy-driven strategies; for instance, to transform from hoe farming to oxen farming or other alternative mechanism. Hence, the current situation of the community and the survey findings vigilant the policymakers to consider the subsistence means of the community while making a decision at macro-level to utilize the forest land of the area by providing for large-scale investors, where the life of the community depends on, to bring a better development options in the country as a whole.

\section{Interaction of Policy-Driven and Autonomous Community Resilience to Climate Variability Adaptation and Mitigation}

The Gumuz community has been excluded from much of the social and economic activities of the main stream society (Abbute 2002). However, there seem to be some changes in this regard in recent years. In view of this, $47.5 \%$ of the respondent households are not aware of having the right to get access to social services. This is despite the fact that our further probing in FGDs and individual interviews showed that their participation does not actually demonstrate equality in the complete sense of the term in any forms of development activities conducted in the area. The development effort seems a top-down approach which overlooks the consent of the beneficiary community. This may have questioned the ownership issues of the development effort under ways in the area. Supporting this statement, Sperling and Szekely (2005) revealed that striking the right balance between top-down commandand-control approaches offer stability over the short term but reduced long-term resilience.

Although limited, improved agricultural practices and technologies, and resettlement programs are the major planed/policy-driven adaptation options promoted to build the resilience of farmers in the areas. Hence, its interaction with community-based adaptation option has discussed. 
Agricultural Practice and Technologies: It was generally agreed that the policy responses to climate change should support and enhance indigenous resilience (UNISDR 2009). In this regards, only 42 households in Guba (both in Mankush and Aysid kebeles), 37 households in Dangur, and 20 households in Debate woredas of surveyed kebeleswere reported as they used improved agricultural technologies since the surveyed period. In this regards, Table 7 shows comparison of the actual observed number of farmers started using of agricultural inputs and animals for farming activities with the total number of households in the sample kebeles. This indicated that only a very small number of farmers, $7.7 \%$ in Debate, $16.2 \%$ in Dangur, and $15.4 \%$ in Guba, started using animals for agricultural farm activities. Hence, the result suggest that revisiting of promotional approaches/system in the way that the Gumuz community awareness level and capacity developed to adopt and use introduced technologies as a planned adaptation options to cope, adapt, and live with the observed and perceived climate variability-induced shocks/stress is indispensable.

In addition, capacity building trainings and awareness rising programs were reported as key intervention underway by the government to improve farmers' perceptions towards improved agricultural technologies. However, $66.4 \%$ of the respondents reported as they lack awareness on the importance of agricultural technologies, while $11.2 \%$ complained unfairness of the available inputs and $15.4 \%$ appreciated the existing natural soil fertility than using the artificial once. FGD participants also indicated that the community also lacks their needs of improved and drought-resistant food crop varieties that require short period of time. In this case the existence of mismatching between the needs of the community to adapt the impact of climate change and the promoted agricultural technologies is acknowledged. For instance, the community needs locally adaptive drought resistance and high-productive food crop varieties than inorganic fertilizer. Indeed, the FGD and KII participants believe that the voices of the community are often unheard. Also they complained about the price of agricultural inputs, which they attributed to difficulties in reaching the poor community groups which is highly vulnerable and/or susceptible to the impacts of climate-induced shocks due to their low adaptive capacity.

Kebele/local-level development agents believed that although a limited effort has been exerted by nongovernmental organization, namely Canadian Physician for Aid

Table 7 Proportion of households who participated in new agricultural technologies

\begin{tabular}{l|l|l|l|l|c}
\hline & $\begin{array}{l}\text { Name of } \\
\text { sampled } \\
\text { Soreda }\end{array}$ & $\begin{array}{l}\text { Sampled } \\
\text { kebele }\end{array}$ & $\begin{array}{l}\text { Total } \\
\text { household }\end{array}$ & $\begin{array}{l}\text { No of household participated in new } \\
\text { agricultural technologies (Agricultural } \\
\text { inputs) }\end{array}$ & $\%$ \\
\hline 1 & Debate & Gessess & 260 & 20 & 7.7 \\
\hline 2 & Dangur & Dibate & 228 & 37 & 16.2 \\
\hline 3 & Guba & $\begin{array}{l}\text { Mankush } \\
\text { zuriya }\end{array}$ & 107 & 14 & 13.1 \\
\cline { 2 - 6 } & Aysid & 224 & 37 & 16.5 \\
\hline
\end{tabular}


and Relief (CPAR) and World Vision (WV) Ethiopia to change the deep-rooted saving culture problem of the Gumuz community in the area through organizing them into saving and credit groups, the involvement of local-level government structure is very limited to scale up this effort besides development of their awareness at all level to diversify means of their livelihood. On top of this, among introduced major agricultural technologies only 78\% use veterinary services followed by pesticides (15\%) and 6.6\% ploughing by animals (Table 8 ). Though maximum efforts have been made by development actors at all level, only $6.6 \%$ used ploughing animals for farming practices.

Most of policy-driven agricultural technologies require intensive farming which do not fit with traditional Gumuz farming practice. They alleged that if they produce agricultural crops more than 2 years on a given plots of land continuously the weed and pest infestation increase which requires additional labor and cost. This also needs ploughing by animals than hoe farming where the Gumuz farmers do not have experience, capacity as well as willingness to adopt. In addition, using of a given plots of land for more than 2 years (for 3 and 4 years) requires seed every year which may also costs the farmers every year. Traditionally, once they sow on a given plots of lands they harvest for consecutive 2 years especially of food crops (sorghum). Although it needs further research, the practice seems to have a considerable role in reducing GHG emission through carbon sequestration.

Metekel zone administrator confirmed the existence of strong tension in breaking the traditional means and adopting the new practice. Shifting of hoe farming to animal farming is not achieved overnight. Enforcement of the existing regional land use polices to implement accordingly in the way that it reduces the existing population pressure on forest resources needs to be capitalized. Also the existence of illegal land grabbing in the zone which were initially entered along with legally registered large-scale agricultural investors as a daily laborer worker needs to be checked and corrected. Currently at local government level they considered the investors as a major cause for devaluation of the traditional Gumuz community means of land management and for the observed poor working culture of the indigenous/Gumuz community. The illegal land holders encourage/initiate the Gumuz people to sell, rent, and provide their lands for share cropping than own farm. In addition, the administrator acknowledged as one of the bottlenecks of providing lands for large agricultural investment in the area. Currently the Gumuz communities especially the youngsters considered themselves as investors, predominantly in Debate and Guba woredas as witnessed by FGD participants.

Table 8 Major agricultural technologies introduced and used by the farmers

\begin{tabular}{l|l|l|l|l}
\hline & Yes & \multicolumn{2}{l}{ No } \\
\cline { 2 - 5 } Technologies & count & $\%$ & Count & $\%$ \\
\hline Veterinary service & 135 & 78 & 38 & 22 \\
\hline Pesticides & 26 & 15 & 147 & 85 \\
\hline Artificial insemination & 2 & 1.2 & 171 & 98.8 \\
\hline Ploughing by oxen/tractor (Agricultural implements costs) & 41 & 6.6 & 57 & 93.4 \\
\hline
\end{tabular}


Because socially in their community they have a right to use their clan land; but currently they started selling, renting, and give for share cropping their clan lands which is large in size/coverage even though traditionally land is not sold under any circumstances either inside or outside the clan of the Gumuz community (Patrick Wallmark 1981).

Hence, the traditional clan land management systems of the Gumuz community is changing with time which may be as a result of population pressures and the extreme climate conditions that forced the highlander immigration to find an alternative means of fulfilling their basic needs and/or provision of forest lands for large-scale agricultural investment.

To this end, it is noted that the community started questioning the government to hear their voice and close a reasonable size of forest land areas for the community. "Head of agriculture and rural development office of Guba woreda confirmed that the land allocation and provision systems for large investors in the area were not considering the local context. Also pointed as, the woreda/distrct officials are exerting their maximum effort in collaboration with zonal and regional government to create a situation in which the local voice should be heard and considered during allocation of large forest lands for investment works. As an adaptation option, promotion of technology transformation from the investor to farmers, establishment of local-level research centers, introduction of appropriate veterinary services, income source diversification through appropriate management of livestock's, and promotion and development of appropriate plan in which the available water sources like Beless, Ayma, and Abay rivers used for irrigation as a major development directions were set at woreda level."

Generally, all policy-driven technologies seem to improve the knowledge and capacity of the community to cope, absorb, and adopt with stress and shocks beside its contribution to increase emission from all land use practices unlike the traditional means. Its rate of promotion is overwhelmed by the current rate of climate variability-induced impacts that threatened the life of the Gumuz people in the areas.

Resettlement: With the objective to introduce improved technology and infrastructure for ensuring food security and to change the lifestyle of the Gumuz ethnic groups, villegization program was initiated by the government and implemented in the area since the year 2012. Most of the farmers were resettled into centralized villages where the water is available or planned to be accessed. However, the FGD participants testified that the community prefers to live in their traditional villages as practiced by their ancestors. Hundred percent of the resettled households whispered as they got no remittance payments made to the community for the resettlement programs. They also mentioned as they face difficulties in identifying what and where to get their needs from forest resources in the new areas since there is no other alternative options to support their ways of life. They also mentioned reduction of forest resources as a result of pressures induced by resettlement program that threatened their life. They reported that women sometimes leave newborns at home to go the whole days for collecting forest products; otherwise there will be no food for the family as a whole. Women were also got difficulties in getting resources to produce different handcrafts, the important economic activity in the area, especially for the women, both for home use and market. Besides its importance in accessing basic socioeconomic services, the program seems 
as it threatened the community traditional means of copping and living with the current and perceived climate variability-induced shocks/stress. In this regard, they are urging revisiting of the program and development of strategic plans that accommodate the interest of the community in supporting their ways of life means in their new areas.

The three key issues that would affect the successful implementation of the planned/policy-driven adaptations options which need the attentions of policymakers when making decision to use the area for other development purpose are identified. The first was the level of technical assistance, given the limited experience and lack of local language knowledge of the government extension workers in the study zone. As a consequence, extension agents do not have skills to train and influence farmers on the adaptations that could be implemented now, or to provide adequate technical support for routine agricultural production practices. Technical assistance from NGOs and community-based extension emphasize that farmer-to-farmer knowledge exchange supported by targeted technical assistance is needed to address the lack of formal extension services.

The second was poor working and saving culture of the community. Since they are highly dependent on forest and forest products they do not have even storage facility for their produces. They store in the farm at field and outside of their village. Also the mens do not have commitment to be engaged on agricultural farm activities alone with his family but women. Their farm activities have been conducted through a self-help group, locally named as "debbo." Debbo requires preparation of local drinks the selfhelp members to conduct agricultural activities for debbo owner. All arrangement and preparation of necessary materials for debbo is the duty of women in the community. Especially during clearing of forest lands, weeding, harvesting, and threshing of crops debbo is must. The farm land size and amount of crop harvested will be also determined by the number of the debbo that a given household would be managed.

Finally, Gumuz farmers lack experience in oxen/animal farming and conducting intensive farm operations besides lack of capacity to have animal or any other small technologies for agricultural farm operation purpose. Malone (2009) indicated that the adaptation process requires the capacity to learn from previous experiences to cope with current climate, and to apply these lessons to cope with future climate, including surprises. Hence, introduction of planned/policy-driven adaptation strategies based on the existing community-based adaptation options that influence the community is indispensable to cope and adapt with extreme weather- and drought-induced shocks/ stress in a sustainable way through building their resilience. In this regard, any policydriven adaptation options that address the above-mentioned key elements are required to improve the adaptive capacity of the Gumuz community in the area.

\section{Conclusions and Recommendations of the Chapter}

\section{Conclusion}

The focus areas of this chapter, Metekel zone, northwest Ethiopia, scrutinized how the Gumuz communities adapt the adverse effects of climate variability and investigated determinants of the use of identified adaptation strategies/options in the area. 
The farmers perceived the declining trends of crop yield, livestock production, and the benefits that community gets from forest resources for the last 5 years. Although it is different among respondents' wealth categories, the existence of food shortage gaps in the community that extends up to 7 months has been identified. The situation is worse in the case of poor community members.

In response to climate change impacts, the Gumuz communities have been practicing different adaptation strategies. Many of the autonomous adaptation responses to the impacts of climate variabilitys/changes include collecting of wild edible plants and other forest products, selling livestock (particularly when they are not likely to get a good price), hunting, renting/selling of farm animals, selling of available household materials and/or equipments, getting support/relay on better-off relatives, and collecting and selling of different wood and wood products (Table 6). In addition, expansion of farm land, usage of drought-resistance crop varieties, replanting/sowing, and changing of sowing calendar are among reported strategies used in response to the impact of climate variability/change. However, the autonomous/community-based adaptation mechanisms have been declining both in type and amount. This is mainly due to provision of forest lands for large-scale agricultural investments and the progressively increasing population pressure. The few households are able to improve their farming practices, for example, in using improved agricultural inputs. Lack of awareness on improved agricultural practices, poor saving, and working culture and dependency on natural resources to fulfill their food shortage gaps were known as the main constraints to adopting these practices. These further resulted in declining of community resilience to the level of crisis which requires direct intervention and support. This calls for a planned action to ensure households meet their consumption needs.

\section{Recommendations}

- Unless communities actively engage in reflexive learning processes about the causes of systemic changes and the links between local and global processes, there is a risk that community resilience becomes nothing more than an illusion. Hence, introduction of awareness raising programs that improve working and saving culture and climate information appear to be important mechanisms as they support the adoption of several adaptation strategies that build community resilience. Special skills training program is keenly important for the local community so that they will participate and benefit from both governmentand private sectors-initiated development programs which are underway in the area.

- The capacity of the community to adopt climate change by using autonomous adaptation is degrading. Therefore, greater effort is needed to increase the resilience of households to cope and adapt with climate variability, through maintaining their autonomous means systematically, and social safety net programming till the community transformed from their autonomous/communitybased means to improved policy-driven adaptation mechanisms and adopt the 
practice besides encouraging accumulation of assets and wealth through diversifying locally adaptive options.

- Given the effect of climate change on crop yields, animal production, and food availability, planned action by government is needed to ensure households meet their consumption needs. This may take the form of protecting the existing natural forest ecosystem where the community can get their day-to-day needs; for example, promotion of bamboo plantation using different plantation strategies since the community has a special attachment with the species to maintain their food security. Other public actions that would increase access to weather insurance for cash crops, of those currently adopted by the community (sesame production) and creating market linkage, early-warning preparedness, and increasing food stockpiles to be used during poor production years need to be considered.

- Besides the available potentials and the existing policy direction at national level, irrigation development interventions are overlooked both at individual and community level in the area. This suggests that investments in irrigation infrastructure would help farmers to engage in higher value crops, thereby increasing farm revenues besides creating alternative farm production for their subsistence life. There is also an identified need for greater investments in promoting appropriate agricultural extension services, locally adaptive and affordable technologies, and accessing local-level research institution to support the effort of the community in availing locally adaptive food crops variety to improve the future well-being of the community in the area.

\section{References}

Abbute W-S (2002) Gumuz and Highland Resettlers: differing strategies of livelihood and ethnic relations in Metekel, Northwestern Ethiopia. PhD Dissertation, University of Gottingen, Gottingen

Alinovi L, Mane E, Romano D (2009) Measuring household resilience to food insecurity: application to Palestinian households. Working Paper. EC-FAO Food Security Programme

Anonymous (2004) Benishangul-Gumuz Regional State Rural Development Coordination Office (2004) Three-year Strategic Plan (2003/04-2005/06)

Anonymous (2011) Benishangul-Gumuz Regional State Food Security and Economic Growth, Canadian based Non-Governmental Organization Five Years Project implementation Plan (2011-2016)

Berhe MG, Butera J-B (2012) Climate change and pastoralism: traditional coping mechanisms and conflict in the horn of Africa. Institute for Peace and Security Studies. Africa Programme, Addis Ababa

Emerta AA (2013) Climate change, growth and poverty in Ethiopia. Working Paper no 3. CCAPS

Esayas A (2003) Soils of Pawe Agricultural Research Center. National Soil Research Center Ethiopian Agricultural Research Organization Technical paper no 78. 23pp

Food Security Strategy, Benishangul-Gumuz, Ethiopia (October 2004) Asossa (unpublished) Global Environmental Change 16:253-267. https://doi.org/10.1016/j.gloenvcha.2006.04.002

IPCC (2007) Climate change 2007: impacts, adaptation and vulnerability. Contribution of Working Group II to the Fourth Assessment Report of the Intergovernmental Panel on Climate Change, 
Annex I (eds: Parry ML, Canziani OF, Palutikof JP, van der Linden PJ, Hanson CE). Cambridge University Press, Cambridge, UK, 976pp

Nyong A, Adesina F, Elash OB (2007) The value of indigenous knowledge in climate change mitigation and adaptation strategies in the African Sahel. Mitig Adap Strat Glob Change 12:787-797

Seo SN, Mendelsohn R (2008) Measuring impacts and adaptations to climate change: a structural Ricardian model of African livestock management. Agricultural Economics, p 38

UNISDR (2009) Terminology: basic terms of disaster risk reduction and IISD et al. 2007. Community-based Risk Screening - Adaptation and Livelihoods (CRiSTAL) User's Manual, Version 3.0

Wallmark P (1981) The Bega (Gumuz) of Wollega: Agriculture and Subsistence; in people and cultures of Ethio-Sudan Borderlands (ed: Bender ML). African Studies Center, Michigan State University, East Lansing, p 79

World Food Program (WFP), Food and Agriculture Organization (FAO) (2012) WFP/FAO Shock Impact Simulation Model for food security analysis and monitoring

Open Access This chapter is licensed under the terms of the Creative Commons Attribution 4.0 International License (http://creativecommons.org/licenses/by/4.0/), which permits use, sharing, adaptation, distribution and reproduction in any medium or format, as long as you give appropriate credit to the original author(s) and the source, provide a link to the Creative Commons license and indicate if changes were made.

The images or other third party material in this chapter are included in the chapter's Creative Commons license, unless indicated otherwise in a credit line to the material. If material is not included in the chapter's Creative Commons license and your intended use is not permitted by statutory regulation or exceeds the permitted use, you will need to obtain permission directly from the copyright holder.

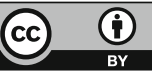

